\title{
Research of the Frost Resistance Durability of Concrete Material Road Engineering
}

\author{
Zhou Yan-hua \\ Jiangxi University of Technology \\ Nanchang Key Laboratory of material and structure detection
}

\begin{abstract}
The concrete structures of mud concrete road and bridge road engineering generally faces serious freezing and thawing damage due to small section, large contact area, and the double role of vehicle load and bad natural environment, as well as the salt used to melt snow in winter. In order to improve the overall level of concrete frost resistance evaluation and concrete frost resistance design of our country's road engineering, through testing system, this paper also studies the influence law to hardened concrete bubble characteristic parameters of gas amount, air-entraining agent varieties, water cement ratio and other factors, which provides reference for concrete frost resistance design, air-entraining agent quality evaluation and the establishment of the relevant specifications. In addition, this papers uses high frequency vibrating rod in the laboratory to simulate high frequency vibrating concrete construction on site and studies the influence of high frequency vibrating to frost resistance of concrete by the influence rules of the time of vibrating to hardened concrete bubble characteristic parameters.
\end{abstract}

Keywords-Concrete; Frost resistance; Bubble characteristic; Air-entraining agent

\section{INTRODUCTION}

With the urban construction and the rapid development of modern transportation, cement concrete is widely used in water conservancy, transportation, industry, civil buildings and other large infrastructure of national economy and the national defense engineering and becomes a kind of irreplaceable building materials. According to preliminary estimates, there is more than 3 billion $\mathrm{m} 3$ production of concrete material per year of the world. As a big country in production and application of concrete, the concrete production of China accounts for about $40 \%$ of the total amount of the world, which is up to
1.2 billion $\mathrm{m} 3$. Because cement concrete has the advantages of wide sources of raw materials, convenient preparation processing, low production costs, especially the low comprehensive energy consumption, many experts and scholars predict that concrete is still the major building material in the 21st century.

With the wide use of cement concrete, however, a growing number of instances show that concrete engineering structures are not durable. Its using time is far shorter than the designed service life, the phenomenon of premature failure have become common. Concrete is facing a serious "crisis" of the durability. These early "senescence" engineering as a result of the durability of concrete does not only need a huge reconstruction and maintenance costs, but also can cause the indirect economic loss and safe hidden troubles. The durability of the concrete has been gravely in front of us, which shall be paid attention to and take measures to improve the durability of concrete.

\section{CONCRETE COMPRESSIVE STRENGTH TEST}

Concrete compressive strength shall be tested with reference to the relevant provisions of "cement and concrete cube compressive strength test method" of Highway engineering cement and concrete test procedures (JTGE30-2005). Specimen shall be made in accordance with the relevant provisions of the concrete shaping and curing methods. When arriving the curing time, specimen shall be taken out from curing room, wipe them to make them clean, measure their size and check their appearance. Discard the ones which are broken. Clamp the specimens on the middle of press plate under press. Put mat between the up and down plates and specimens. The pressure surface of specimens shall be vertical to the top after molding. Start the machine to make specimens be pressed 
by uniform compression. Load the specimens with the speed of $0.3 \mathrm{MPa} / \mathrm{s} \sim 0.5 \mathrm{MPa} / \mathrm{s}$ continuously and evenly. When specimen are damaged or start deforming quickly, stop adjusting throttle, until the specimen damage. The breaking load shall be recorded. The cube specimens with the side length of $100 \mathrm{~mm}$ shall be used in test. The test results are multiplied by the coefficient factor 0.95 . Concrete cube compressive strength shall be calculated by formula (correct to $0.1 \mathrm{MPa}$ ).

$$
f_{c c}=\frac{p}{A}
$$

In formula: $f_{c c}$ Compressive strength, MPa;

$\mathrm{P} \_$Breaking load, $\mathrm{N}$;

A - Specimens confined area, $\mathrm{mm}^{2}$

The average value of three specimens measured shall be the compressive strength test results for this group of specimens. When the difference between one of the maximum or minimum value of the three specimens intensity and the intermediate value is more than $15 \%$ of the median value, the middle value shall be taken. When the difference between the maximum and the minimum of the three specimens intensity and the intermediate values is more than $15 \%$ of the median value, this test will be done again.

\section{CONCRETE FROST RESISTANCE TEST}

Take three specimens as a group and conduct freezing and thawing test after 28 days of curing specimens. Specimens shall be taken out from the curing place 4 days before the test and soak them in water of $20+/-3{ }^{\circ} \mathrm{C}$ for 4 days. Then wipe the water of the surface of specimens and measure the initial weight. According to "Concrete dynamic elastic modulus test", test the initial natural frequency as the initial value to evaluate frost resistance. Make the necessary appearance description or take pictures.

Then put specimens into specimen box, and inject fresh water, making the water immerse $20 \mathrm{~mm}$ of the top of specimens. Freezing and thawing test begins. A freeing and thawing test lasts about 3 hours, during which time specimens are in saturated state. The temperature of specimen centers shall be $\left(-17 \pm 2^{\circ} \mathrm{C}\right)-\left(8 \pm 2^{\circ} \mathrm{C}\right)$. Check specimens once each 25 times of freeze-thaw cycles. Assess the freezing-thawing resisting performance of concrete according to relative dynamic elastic modulus, weight losses rate and relative durability index.

Freezing and thawing test shall be stopped when one of the following conditions appears:

(1) Freezing and thawing tests have been done 300 cycles;

(2) Relative dynamic elastic modulus decrease to $60 \%$ of the initial value;

(3) Weight loss rate reaches 5\%. The relative dynamic elastic modulus $\mathrm{P}$ can be calculated by the formula:

$$
P=\frac{f_{m}^{2}}{f_{0}^{2}} \times 100
$$

In formula: $\mathrm{P}$ The relative dynamic elastic modulus of specimens after $\mathrm{n}$ times of freezing and thawing $(\%)$;

$f_{n} \_$Natural frequency of vibration after $n$ times of freezing and thawing $(\mathrm{Hz})$;

$f_{0} \ldots$ Natural frequency of vibration before test (Hz).

Weight losses can be calculated by:

$$
W_{n}=\frac{m_{0}-m_{n}}{m_{0}} \times 100
$$

In formula: $\mathrm{W}$ _ The changing rate of the weight of specimen after $\mathrm{n}$ times of freeing and thawing (\%);

$m_{0} \_$The weight of specimen before freeing and thawing $(\mathrm{kg})$;

$m_{n}$ The weight of specimen after $\mathrm{n}$ times of freeing and thawing $(\mathrm{kg})$.

The mechanism of concrete freezing and thawing destruction

In 1945, Powers of of the United States put forward hydrostatic pressure assumption which damages concrete freezing and thawing. Then he, with Helmuth, put forward 
osmotic pressure assumption. The two assumptions more successfully explain the mechanism of concrete freezing and thawing damage and establish the essential theoretical foundation of the frost resistance of concrete. Concrete freeze-thaw damage process is shown in Fig .1.

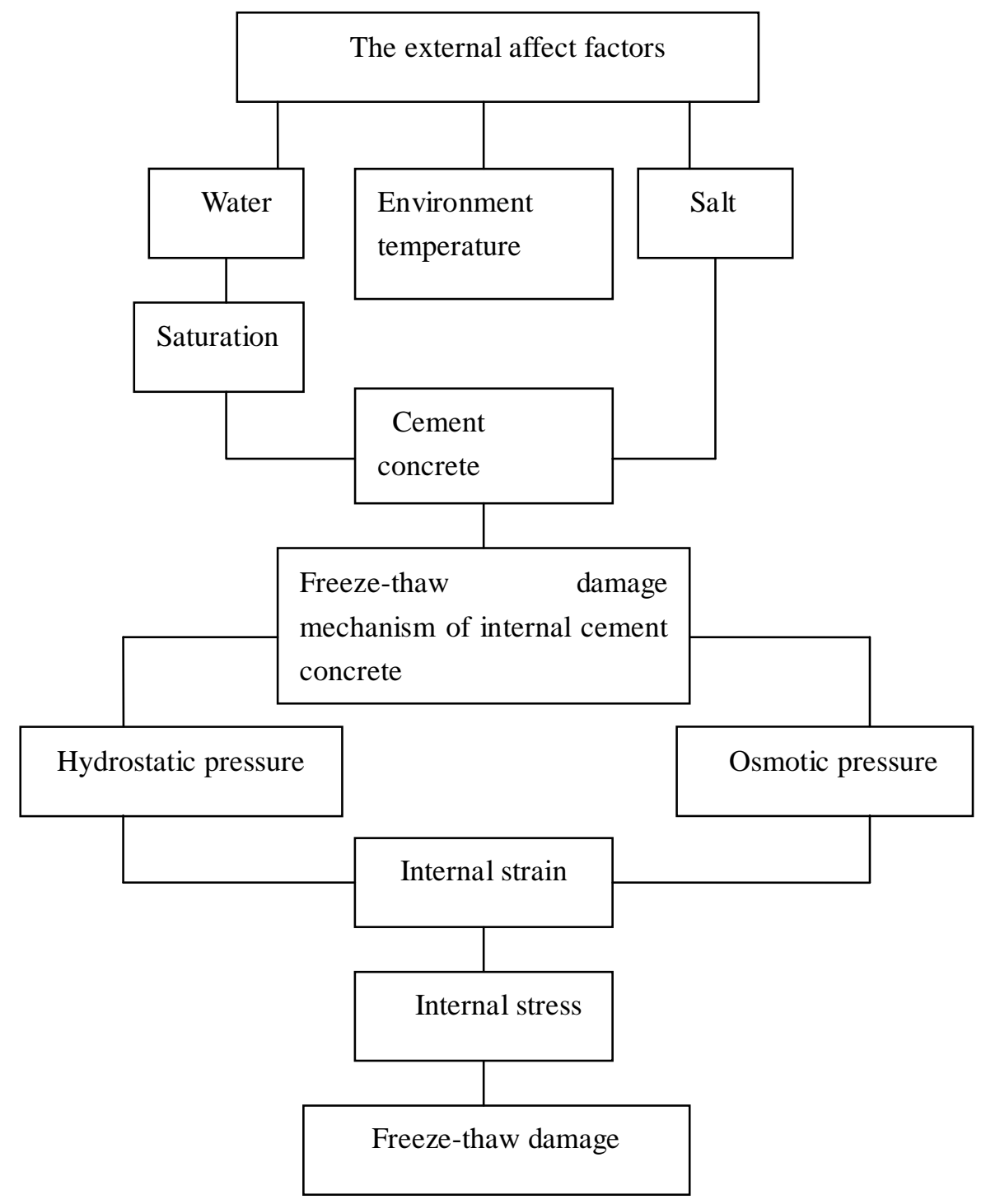

Figure 1. Freeze-thaw damage process figure of concrete

\section{A. Hydrostatic pressure assumption}

Porosity of hardened concrete contains gel holes, wool stoma, air bubble, etc. The size of various pore has large difference. The aperture of gel hole is $15 \sim 100$; Wool stoma is commonly $0.01 \sim 10 \mu \mathrm{m}$ which are often connected to each other; Air bubbles are introduced naturally or introduced artificially by adding air-entraining agent and are commonly shown in sealed routine spherical. The wool stoma concrete is in saturated state when concrete is in water. The lining of the air bubble has adsorption of water, but it is difficult to reach saturation under atmospheric pressure.

\section{B. Osmotic pressure assumption}

Hydrostatic pressure assumption successfully explains many phenomena in the process of freezing and thawing process of concrete, such as the role of air-entraining agent, the influence of ice velocity speed on frost resistance, etc., but it cannot explain some important phenomena, such as concrete will not only be damaged by the freezing of water, but also by the freezing processes of organic liquid such as benzene and chloroform whose volume is not disrupted by frozen and the shrinkage of air-entraining slurry in the freezing process. Based on this, Powers and Helmuth put forward osmotic pressure assumption. 


\section{CONCLUSION}

Through the study of the paper, the main results are as follows:

According to the specific condition of the concrete materials of our country, comprehensively consider water cement ratio, air content, air-entraining agent varieties, through a large number of trials, the correlation curve between concrete bubble interval coefficients and frost resistance durability index is obtained. Frost resistance durability index decreases as concrete bubble interval coefficients increases. Through research, the paper carries on the elaboration on bubble interval coefficients and puts forward evaluation procedures and methods of the frost resistance of concrete tested by automatic equipment based on hardening concrete bubble structure features.

After appropriate high-frequency vibrating, although the air content of concrete loses largely, the bubble area increases, the bubbles interval coefficients change little. With the increase of the high frequency vibration time, the total number of bubbles and the number of small bubbles (with the diameter of less than $120 \mu \mathrm{m}$ ) in the hardened concrete will reach a peak then decrease dramatically. Therefore, controlling the high frequency vibrating time in a reasonable scope is conducive to improve the bubble structure of air-entraining concrete and will not be harmful to the frost resistance.

\section{REFERENCES}

[1] Neville A M. Properties of Concrete[J]. Properties of Concrete, 1996, 36(4):838-844

[2] Mander J B, Priestley M J N, Park R. Theoretical Stress-Strain Model for Confined Concrete[J]. Journal of Structural Engineering, 1988, 114(8):1804-1826.

[3] Graham R L, Knuth D E, Patashnik O. Concrete Mathematics[J]. Concrete Mathematics A Foundation for Computer Science, 1994.

[4] Hillenborg A, Modeer M, Petersson P E. Analysis of Crack Formation and Crack Growth in Concrete by Means of Fracture Mechanics and Finite Elements[J]. Cement \& Concrete Research, 2008, 6:773-781.

[5] Graham R L, Knuth D E, Patashnik O. Concrete Mathematics: A Foundation for Computer Science[J]. Computers in Physics, 1989, 3(5):106-107.

[6] Paulay T, Priestley M J N. Seismic Design of Reinforced Concrete and Masonry Buildings $[\mathrm{J}]$. Seismic Design of Reinforced Concrete \& Masonry Buildings, 1992, (1):49-56.

[7] Zdeněk P. Bažant, B. H. Oh. Crack Band Theory for Fracture of Concrete[J]. Materials Is\&lsstructures, 1983, 16(3):155-177.

[8] Vecchio F J, Collins M P. The Modified Compression-Field Theory for Reinforced Concrete Elements Subjected to Shear[J]. Aci Structural Journal, 1986, 83:219-231.

[9] Park Y J, Ang H S. Mechanistic Seismic Damage Model for Reinforced Concrete[J]. Journal of Structural Engineering, 1985 111(4):722-739.

[10] Bažant, Z. P, Planas J. FRACTURE and SIZE EFFECT in concrete and Other Quasibrittle Materials[J]. Epfl, 1998.

[11] Mander J B, Priestley M J N, Park R. Observed Stress-Strain Behavior of Confined Concrete[J]. Journal of Structural Engineering, 1987, 114(8):1827-1849.

[12] Bakis C E, Ganjehlou A, Kachlakev D I, et al. Guide for the Design and Construction of Externally Bonded FRP Systems for Strengthening Concrete Structures[J]. Proc.int.symposium on Frp Reinforcement for Concrete Structures, 2002, 440. 